\title{
THE IMPACT OF INTERNET USAGE ON HEALTH-CARE EXPENDITURES AND SUSTAINABILITY
}

\author{
Marco Benvenuto ${ }^{1}$ \\ Francesco Vincenzo Sambati \\ Carmine Viola ${ }^{3}$
}

DOI: https://doi.org/10.31410/ERAZ.S.P.2019.95

\begin{abstract}
Introduction: The increasing age, the presence of different diseases that affect the health of individuals and the new opportunities of access to information are changing the process of acquisition of data on health status. Very often, the process of autonomous research of information leads to wrong self-diagnosis with consequent repercussions on health expenditures (e.g.: unnecessary hospitalization) and, generally, on sustainability of health systems.
\end{abstract}

Scope: This work aims to examine the influence of Digital Divide and Internet Usage (DD/IU) on autonomous Health Information Seeking (HIC) process, in order to get useful information about its impact on Healthcare Expenditures per Individual (HEPI). Similarly, this work aims to recognize and understand, from an economical, organizational and technological perspective, the correlation between DD/IUHIS and HEPI.

Methods: To discover the link between DD/IU, HIS and HEPI, we conducted a systematic literature review in order to understand the network of behind these concepts and we applied the Panel Linear Model (PLM) approach in a case study to prove the correlation.

Findings: By analysing the literature on between DD/IU and HIS ties have emerged between the research topics. These findings have been also revealed by a significative impact. This suggests that, since people live longer, the more individuals access the Internet to get information on health status, the more effective the health expenditure is. All of this has repercussions on the long-term sustainability of the health system, requiring a re-modulation of the services provided, the professionalism and the technologies adopted.

Keywords: Digital Divide, Health Information Seeking, Health-care Expenditures, Internet Usage, Internet Access.

\section{INTRODUCTION}

$\mathrm{W}$ orldwide health and health conditions are changing. According to WHO's statistics, indicators such as Life expectancy at birth or Healthy life expectancy at birth are showing significant increase (respectively from 66,5 years in 2000 to 72,0 in 2016 and from 58,5 in 2000 to 63,3 in 2016). According WHO's report[1], that analyzed health statistics for its 194 Member States, focusing on the health and health-related Sustainable Development Goals (SDGs), these improvements can be ascribed to: a global enhancement of reproductive, maternal, newborn and child health; a reduction of incidence of infectious diseases, such as HIV ("from 0.40 per 1000 uninfected population in 2005 to 0.26 per 1000 uninfected population in 2016") or TB (with a $19 \%$ decrease of new and relapse cases from 2000 to 2016); a collective reduction of mortality

1 UNISALENTO, Centro Ecotekne Pal. C - S.P. 6, Lecce - Monteroni, CAP 72023 - ITALY

2 UNISALENTO, Centro Ecotekne Pal. C - S.P. 6, Lecce - Monteroni, CAP 72023 - ITALY

3 UNISALENTO, Centro Ecotekne Pal. C - S.P. 6, Lecce - Monteroni, CAP 72023 - ITALY 
due to the four main Non-Communicable- Diseases (NCDs) ${ }^{4}$ in people from 30 to 70 years; universal health coverage (there is an enormous heterogeneity between countries); a gradual growth of essential services provided by national health services; and a constant increase in financial resources spent on research and development to develop or create new health products and processes.

Nowadays digital transformation is changing our life and our well-being, in a relatively short time it has changed unprecedented the way people work, interact, and learn [2]. In fact, past global revolutions (e.g. Industrial Revolution) produced their effect slowly and with great heterogeneity in countries.

Recently, OECD[3] analyzed how digital technologies are changing and will change our life. In its report, OECD starts its considerations from some empirical evidences: people are making a constant use of personal digital devices to access the Internet; broadband connections increased by $26 \%$ in OECD countries; applications, such as Big data [4], Internet of Things, and Artificial Intelligence, connected to the widespread technologies are continuously developed.

Extreme use of digital technologies and connection, to date, is deeply connected to information and exchange of communications. On one hand, in health-care delivery most common application are: electronic health records, online accessibility of health-care providers, remote sensors, eHealth technologies [5], and medical appointments online. On the other hand, digitalization is leading to better outcomes of health technologies (such as, reduction of costs and effectiveness in management of pathologies) [6],[7] and to improve patient experiences (for example, with online platform upon which individuals can find more information about diseases, treatments or support) [8].

In other studies [4], [9] it emerges that digital devices and the Internet connection caused disparities in Internet usage and Internet access, between countries and within countries: these phenomena are known as Digital Divide (DD). The DD is related to three key elements: technology (infrastructure[10] and hardware[11]), Socio-economic impact (social inequalities: class, ethnicity, gender, age, and geographical location [12], [13]), and Ability to use the devices (First Level DD [9], [14] and Second Level DD[15], [16]).

For the reasons exposed above, this paper aims to investigate the impact of DD and Health Information Seeking Online (HIS) among individuals on individual health-care expenditures. Due to the complexity of the subject matter, we followed a tiered approach, dividing the research work into two steps. First, we identified through a literature review the hidden relationship among the determinants of DD and HIS and the variables needed. Then we applied a Panel Linear Model (PLM) on an empirical research on European individual health expenditures.

This paper is organized as follows: the introduction presents the information needed to introduce the research questions; a brief literature review to identify the concept and the variables; the PLM methodology adopted to analyse the data; the results and the conclusion.

$4 \quad$ The four main NCDs are: cardiovascular disease (with 44\% of all NCD deaths); cancer (22\%); chronic respiratory disease $(9 \%)$; and diabetes $(4 \%)$. 


\section{BRIEF LITERARATURE REVIEW}

\subsection{Literarature review metodology}

We analysed scientific production using the "Digital Divide", "Internet Usage" and "Health Information Seeking" descriptors. The research was performed using the ISI Web of Knowledge database, focusing on material published between 2012 and 2019. We chose to limit our research with articles from 2012 because in that year in the World Economic Forum was presented officially presented the "digital divide" as "inequalities between the advanced economies and the rest of the world in terms of access and use of information and communication technologies (ICT), and thus its economic and social impacts" [17]. We downloaded the .cvs file containing all the information provided by the Isi Web of Knowledge database.

The study also established some exclusion criteria:

1. From 129 documents found on ISI, we removed 14 of them because of lack of digital Object Identifier;

2. The second criterion of exclusion is the keywords used to characterize the abstract, using a Rstudio and text analysis packages we select articles containing the following keywords: digitality, digitalization, divide, Internet, technologies, technology, technology based, mobile, access, devices, inequality, accessibility, health, health-care, health seeking, information, information seeking, seeking, care, search, research, medical, needs, disease, chronic, illness, patient, and inequalities. We removed 9 articles.

3. In the third phase, based on screening on abstract we selected 65 documents (59 available documents).

4. In the fourth and last phase, we read 59 documents and we admitted 11 articles in the study, in order to extract definitions, determinants and variables useful to decline DD and HIS.

\subsection{Definition and determinants of digital divide}

After 2012, first authors that recognized the impact of DD are Broadbent and Papadopoulos[18], they affirmed that two elements characterized it. The first is "infrastructure", the "access to ICT infrastructure in the digital age is fundamental to reducing economic and social disparity", but it is not sufficient. The second element is "Capacity for ICT access", they referred to the availability of devices to use "infrastructure". These phenomena appeared in different social situations (e.g.: low income, unemployed, elderly, disabled, low language proficiency, and those in rural or remote areas), both in developed and in developing countries. Neumark [19], citing other authors, listed different barriers about Internet use for health: limited Internet access and connectivity (what has come to be termed first-level DD[9]); insufficient web-navigation skills (second-level DD[11]), lack of privacy, time constraints, financial costs of going online, language challenges, lack of trust in the Internet as a reliable source of health information, etc.

Choudrie et al[20] confirmed that the two elements of DD (i.e. technology usage and infrastructure) are the main barriers when we talk about the modern way of interaction within people and between people and government agencies (or health-care providers)[21], [22],[23].

\subsection{Definition and determinants of health information seeking online}

Health Information Seeking is one of the most relevant activity online, especially among adult and older people. 
Feng [24], citing other authors, defined Health information as" any information which is related to the practice of medicine and health-care" and "information which can aid in the prevention, detection, and treatment of disease". He noticed that Internet has changed the way to find information, providing the widest, up-to-date and easy-to-access information to clinicians and patients. He also highlighted that the Internet penetration, among American homes, has revealed a problem with the skills needed to find, evaluate and understand information (especially health information). Contextually, the increasing age (older people) and the incidence of chronic diseases increased the likelihood to seek out health related news and information.

Sato[25] highlighted that social network, and the related exchange and search of information on the Internet, increased the use of devices and mobile devices. The author specified, "[...] 31\% of cell phone owners, and 52\% of smartphone owners, have used their phone to look up health or medical information".

Hallows[26] stated that the Internet has become the most popular destination about health information, also in elderly users because they are interested in maintain their health conditions and/ or in management of their chronic diseases. The author, reporting a research of 2009 , underlined that online health information is the third most popular online activity among seniors.

Shah and Marchionini[27] report that "members of medically underserved groups are less likely to use the Internet for health information", that Internet access is preparatory to online health information search and that Internet use (time, frequency, or activities) is related to the frequency of online health information search.

The problem of misinformation and information overload due to a wrong interpretation of information could be possible but, in general, it is less common because to the cross checking information [28], in fact consulting different online sources can lead to identify the correct evidences and to isolate the wrong ones.

\section{CASE STUDY}

In order to investigate the influence Because of interdependencies between our variables and mutual impact between, we have decided to use a Panel linear model regression (PLM). Therefore, we taken 23 cross-sections to the European member states in a period across 10 years, from 2007 to 2016. We excluded five states because of the complete lack of data in OECD datasets. We treated missing value (complete lack of HIS in 2012 and 2014, and of CatH in 2014 and 2016) with interpolation function (imputeTS package) in $\mathrm{R}$ in order guarantee the completeness of data.

\subsection{Data and variables description}

Using both OECD and EUROSTAT datasets, we identified six main variables. They are:

- Current expenditure on health (HEPI), this variable consider the expenditures per capita at current prices [OECD, Dataset: Health expenditure and financing];

- Households with Internet access at home (IA), as the percentage of individuals with an Internet connection at home. This variable does not consider technological difference between, for example, classical DSL and xDSL [OECD, Dataset: ICT Access and Usage by Households and Individuals]; 
- Individuals frequently using Internet (IU), it refers to individual from 16 to 74 years connection to the Internet every day or almost every day on average within the last 3 months before the survey. Use includes all locations and methods of access and any purpose (private or work/business related). the value is expressed in percentage [EUROSTAT, Dataset: Individuals frequently using the Internet].

- Households with computer access at home (CatH), it expresses the percentage of individuals with a computer at home [OECD, Dataset: ICT Access and Usage by Households and Individuals] ;

- Individuals using the Internet for seeking health information - last $3 \mathrm{~m}$ (HIS), this include all the searches on Internet in the last 3 months before the survey. These researches include all the topics related to health and health-care (injury, disease, nutrition, improving health, etc.). The value is expressed in percentage [OECD, Dataset: ICT Access and Usage by Households and Individuals];

- Life expectancy at birth (LEX), it measures how many years an individual is expected to live at birth [OEDC, Dataset: Health Status].

The data presents a great heterogeneity both between country and within time. In fact, observing the descriptive statistics (Table 1 - Descriptive statistics), you can see a constant increasing mean value about IU, IA and $\mathrm{Hi}$, on the other side the Heterogeneity across years about HEPI increased less rapidly than the other variables while the distance between the minimum and the maximum value increases (Figures 1-4).

Table 1: Descriptive statistics

\begin{tabular}{|l|r|r|r|r|r|r|r|r|}
\hline Variable & $\mathbf{N}$ & Mean & Std. dev. & Min. & $\mathbf{2 5 \%}$ & Median & $\mathbf{7 5} \%$ & Max. \\
\hline HEPI & 230 & $1,961.832$ & $1,228.220$ & 320.850 & 771.615 & $1,831.720$ & $2,929.540$ & $5,014.740$ \\
\hline IU & 230 & 58.587 & 15.876 & 19.000 & 47.000 & 59.000 & 70.000 & 93.000 \\
\hline CatH & 230 & 76.517 & 12.598 & 40.170 & 67.483 & 78.910 & 87.387 & 96.200 \\
\hline IA & 230 & 72.730 & 14.821 & 25.400 & 62.763 & 74.655 & 82.945 & 97.040 \\
\hline HIS & 230 & 40.172 & 12.738 & 7.660 & 31.620 & 40.780 & 48.915 & 70.720 \\
\hline LEX & 230 & 79.365 & 2.858 & 70.800 & 77.450 & 80.500 & 81.300 & 83.400 \\
\hline
\end{tabular}

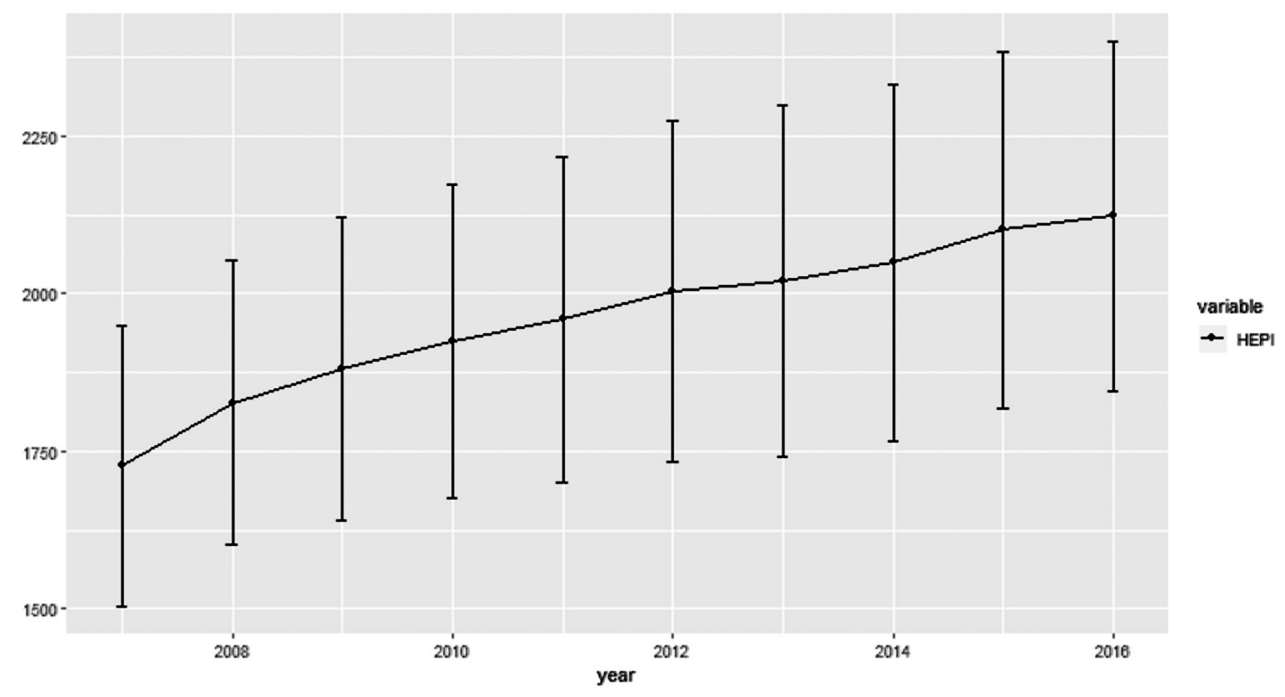

Figure 1: Health Expenditures per Individual over years 


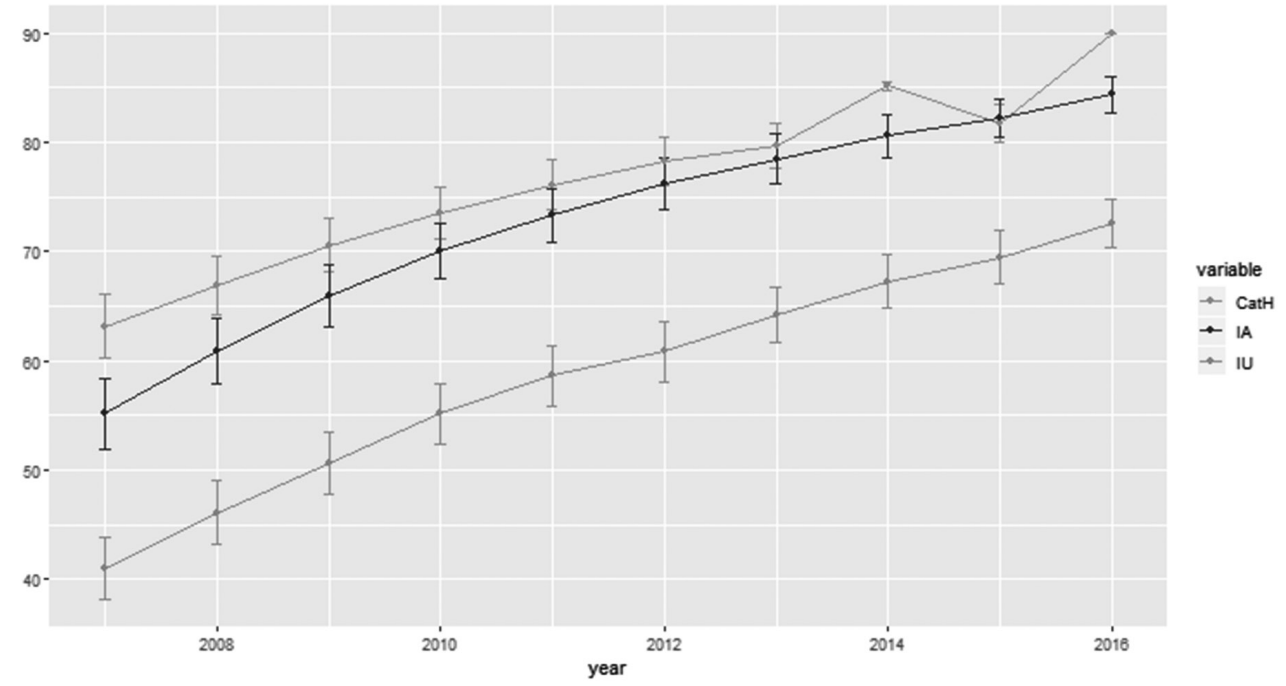

Figure 2: Computer at Home (CatH), Internet Access (IA) and Internet Usage (IU) over Years

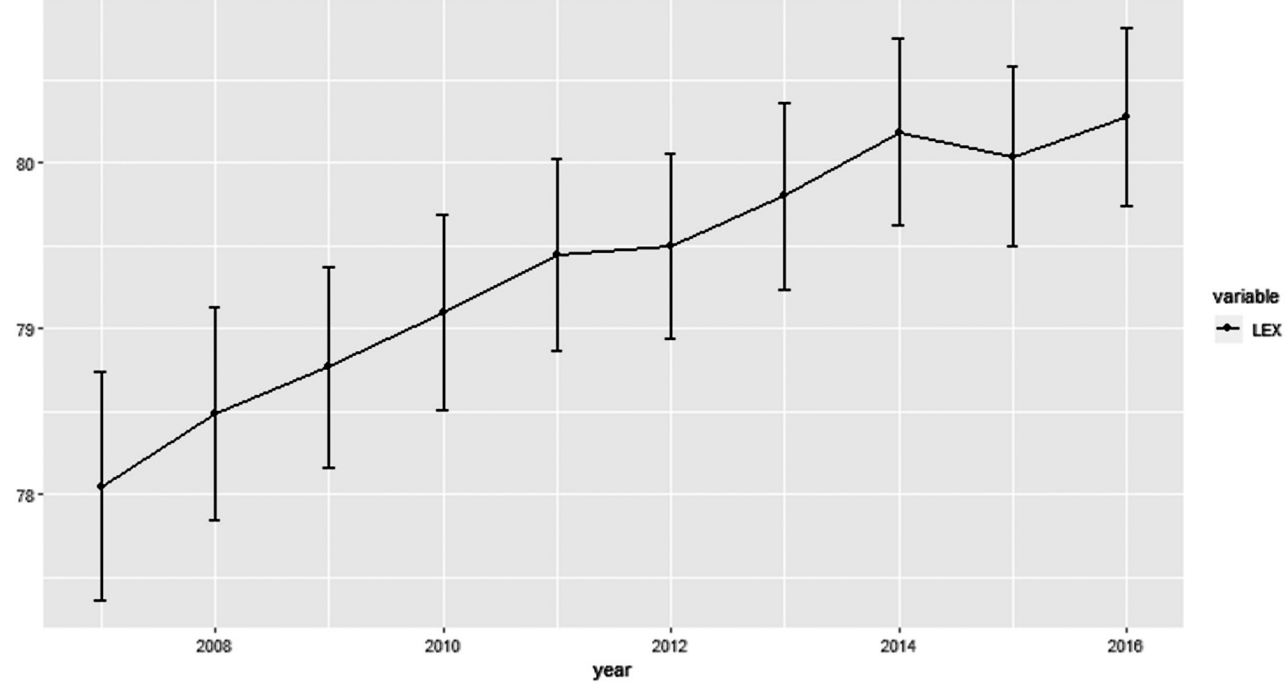

Figure 3: Life Expectancy over years

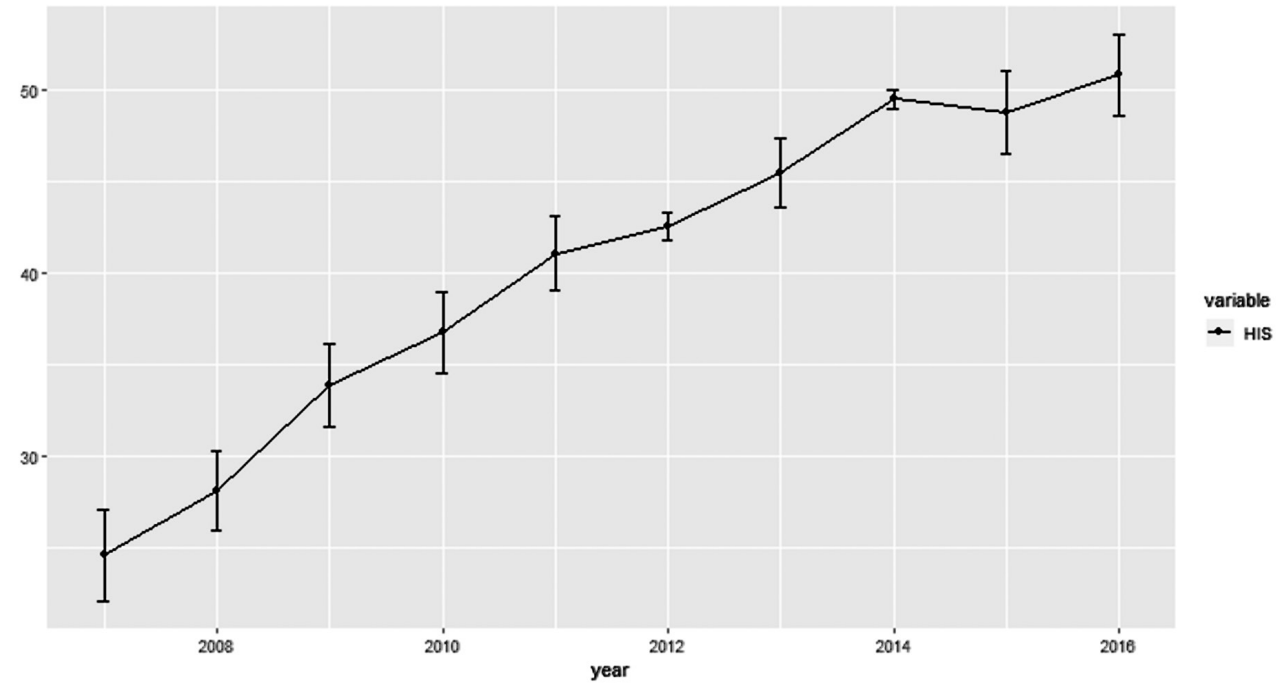

Figure 4: Health Information Seeking over years 
The differences are much more evident when you look about the heterogeneity across country (Figures 5-10). In this perspective, it arises a great disparity in IA, IU and HI on the two European poles (the Mediterranean and the North Europe). Countries, with lowest levels of Internet access, highlight low levels of Internet usage and are less confident finding autonomously health information on the Internet. In the last figure, the distinction between the Mediterranean and the North Europe is sharpest. Low level of HEPH could be caused by low opportunity to access to the Internet, consequently to use it and to find and to consult online health information.

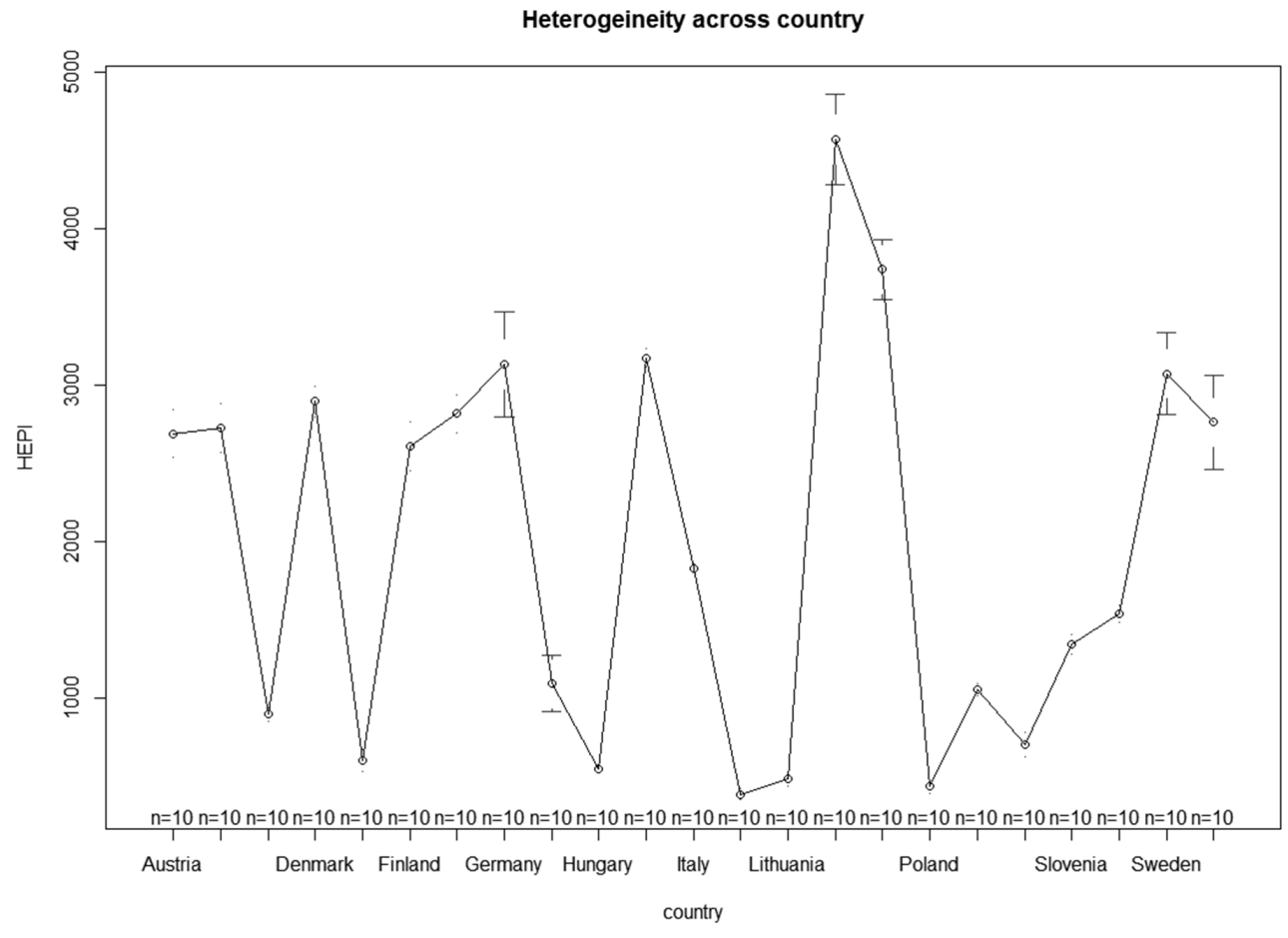

Figure 5: Health Expenditures per Individual across countries

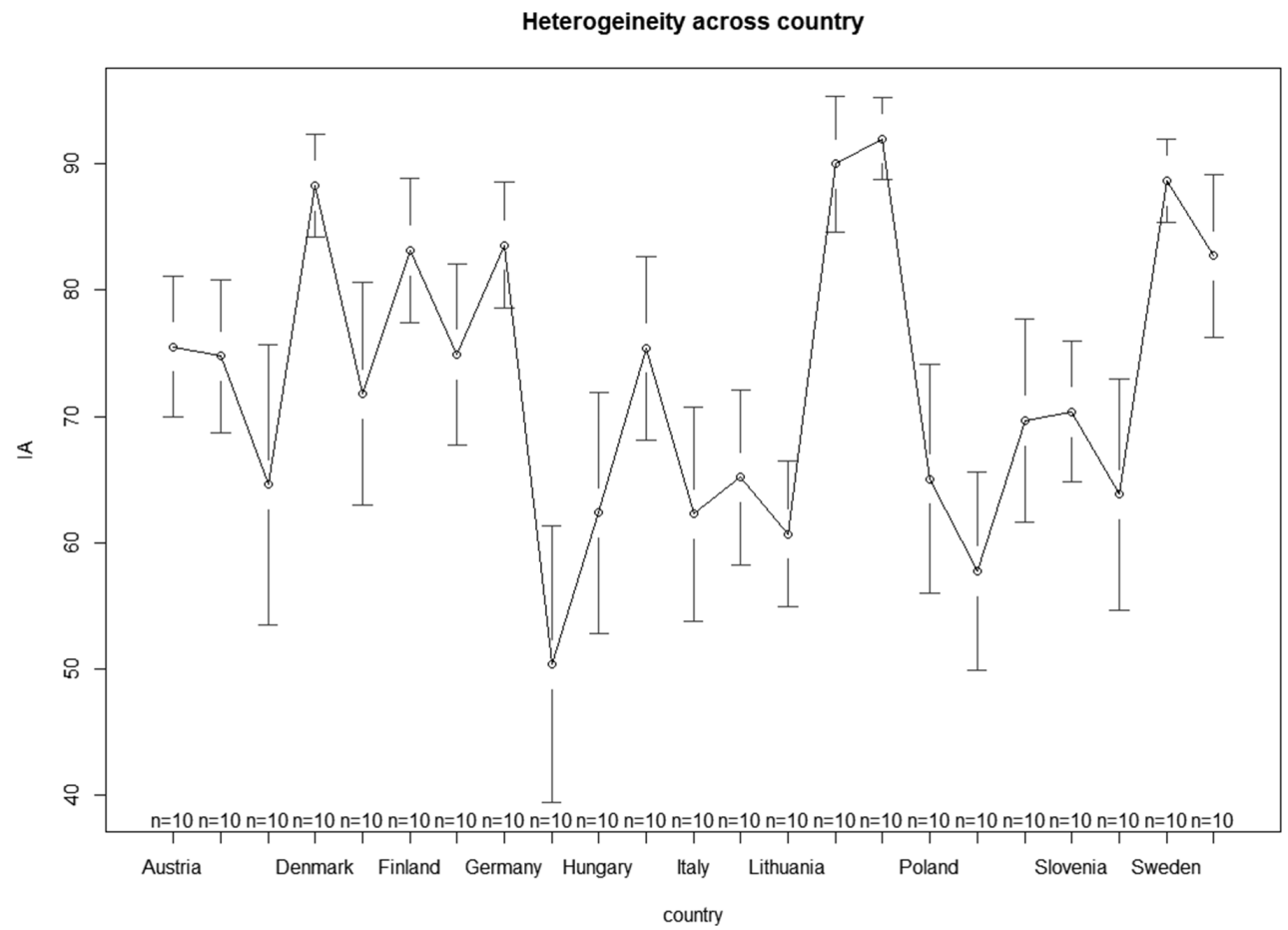

Figure 6: Internet Access across countries 
ERAZ 2019

Selected Papers

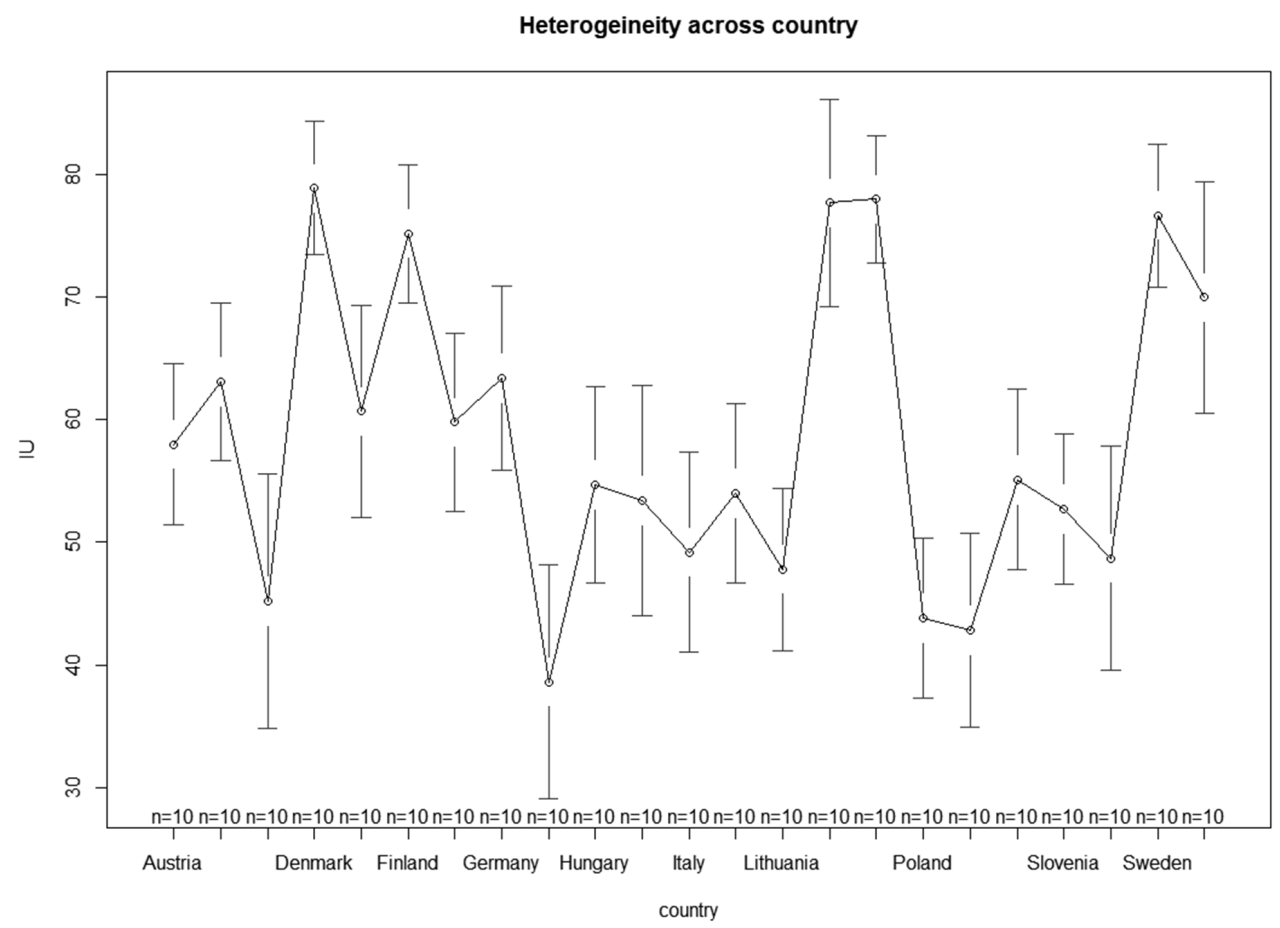

Figure 7: Internet Usage across countries

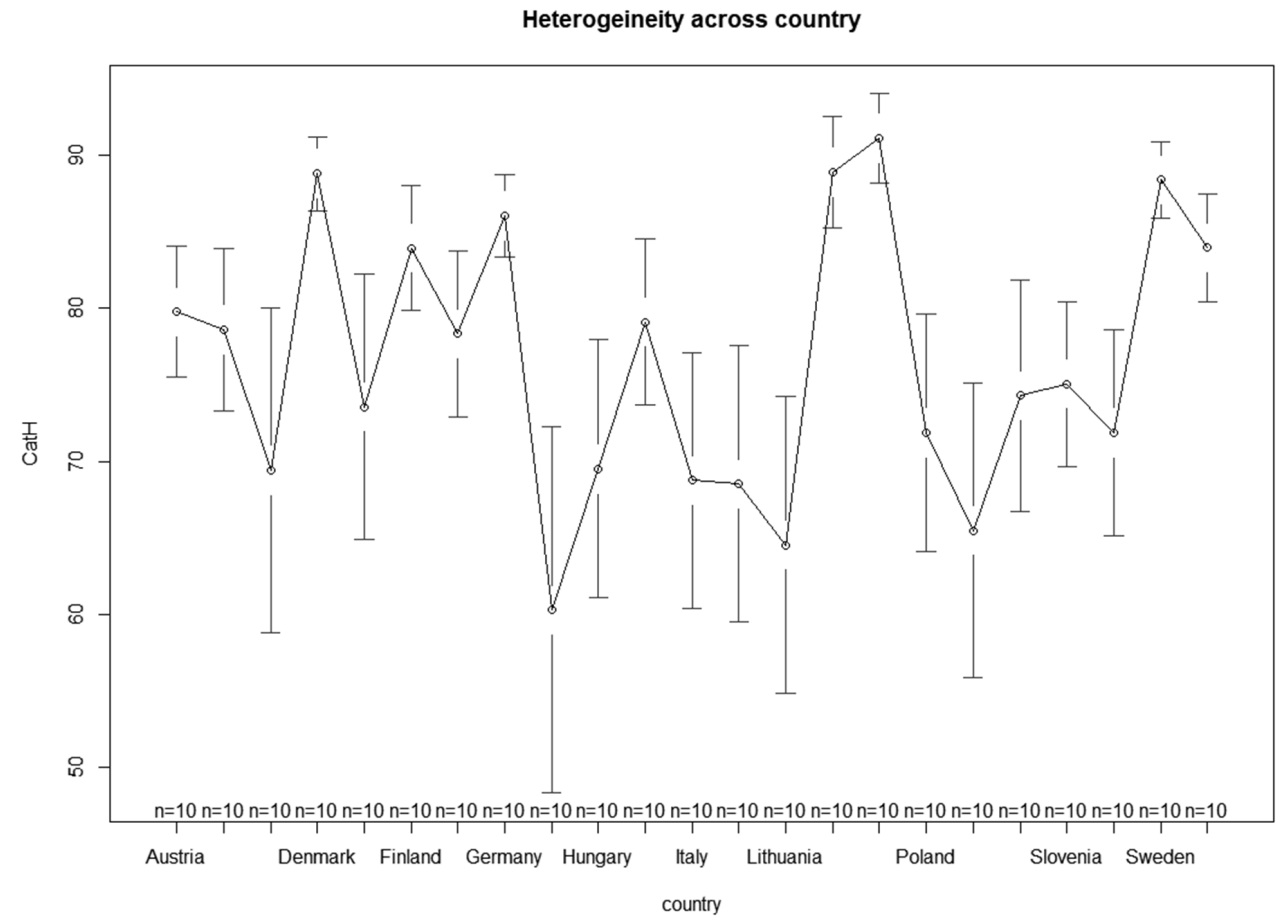

Figure 8: Computer at Home across countries 


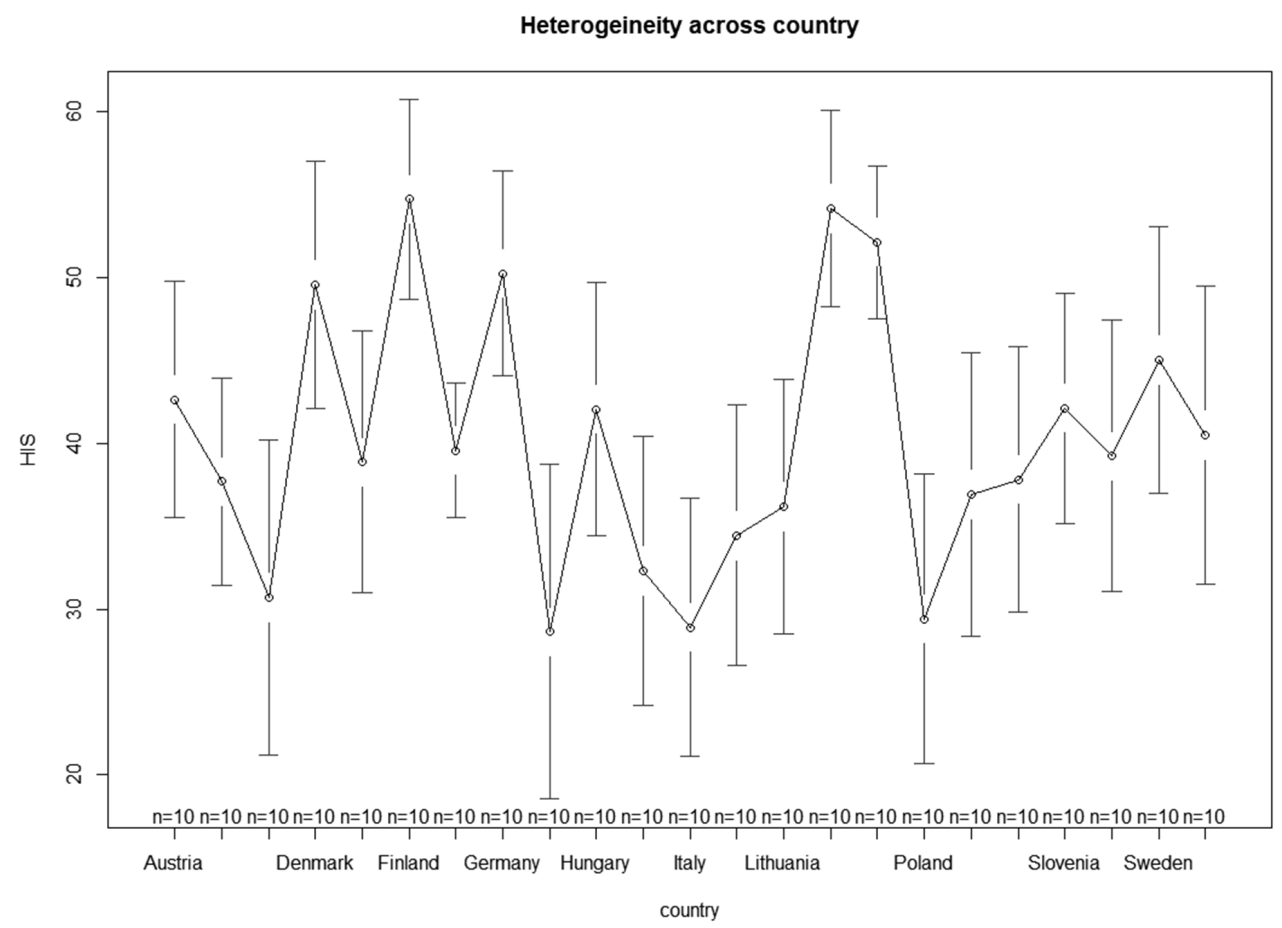

Figure 9: Health Information Seeking across countries

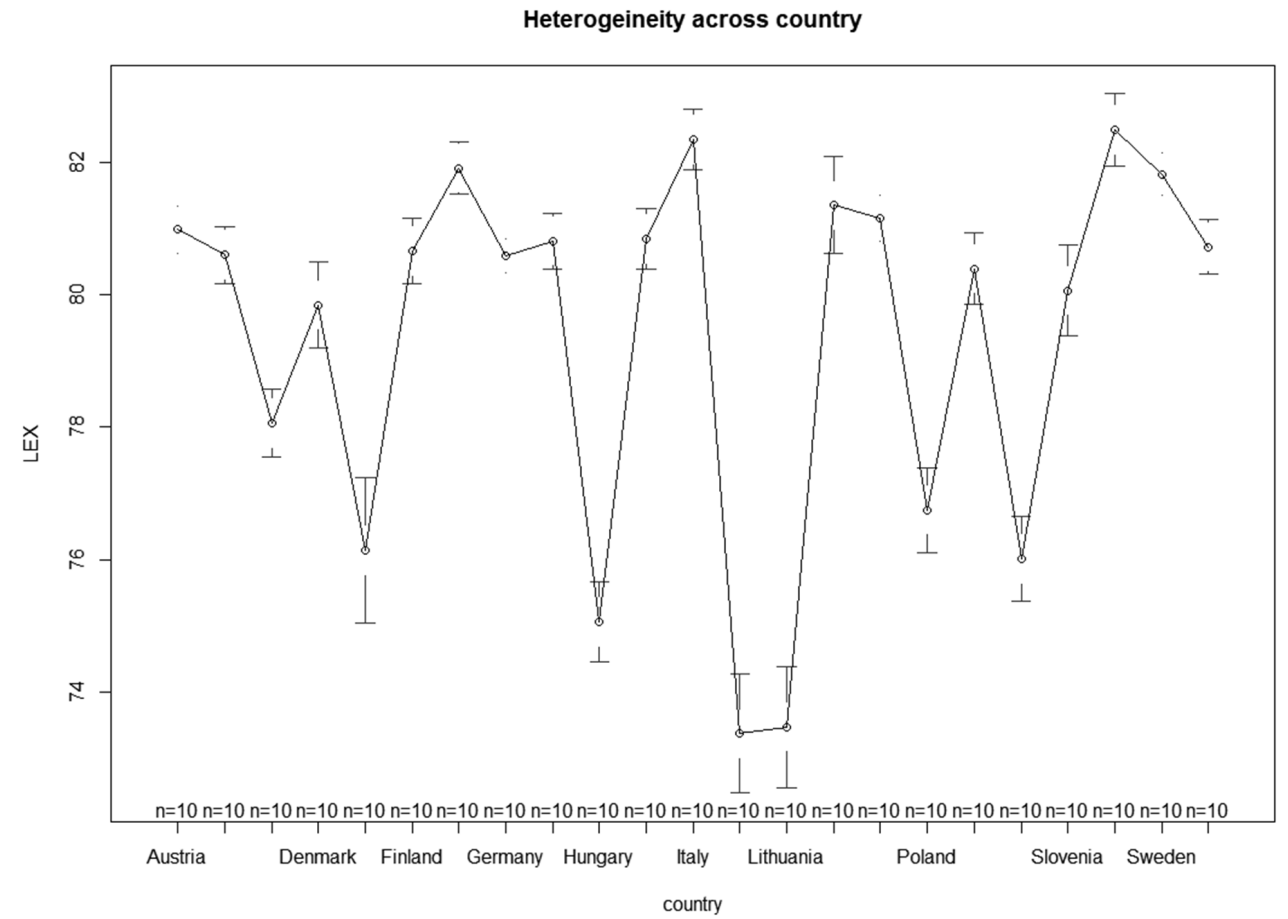

Figure 10: Life Expectancy across countries 


\subsection{MODEL DESCRIPTION}

PLM are the most used models in panel data analysis and with specific test will allow us to identify which model fit better the data and if there are country effects[29].

Starting from the classical linear model

$$
\mathrm{y}_{\mathrm{it}}=\alpha_{\mathrm{it}}+\beta_{\mathrm{it}}^{\mathrm{T}} \mathrm{x}_{\mathrm{it}}+\mathrm{u}_{\mathrm{it}}
$$

where $\mathrm{i}=1, \ldots, \mathrm{N}$ is the is the individual (group, country...) index, $\mathrm{t}=1, \ldots, \mathrm{T}$ is the time index and a random disturbance term of mean 0 , we hypothesized the following model to describe the relationship between the variables listed above:

$$
\mathrm{HEPI}_{\mathrm{it}}=\alpha_{\mathrm{it}}+\beta_{\mathrm{it}}^{\mathrm{T}} \mathrm{IA}_{\mathrm{it}}+\gamma_{\mathrm{it}}^{\mathrm{T}} \mathrm{IU}_{\mathrm{it}}+\delta_{\mathrm{it}}^{\mathrm{T}} \mathrm{CatH} \mathrm{it}_{\mathrm{it}}+\zeta_{\mathrm{it}}^{\mathrm{T}} \mathrm{HIS}+{1_{\mathrm{it}}^{\mathrm{T}}}^{\mathrm{T}} \mathrm{LEX}+\mathrm{u}_{\mathrm{it}}
$$

The model was studied according the three classical approach:

- Pooling model (OLS);

- Fixed effect model (either "individual effect" and "time effect";

- Random effect.

The hypotheses on parameters and error terms (and hence the choice of the most appropriate estimator) was tested by means of:

1. F-test (let you choose between OLS and Fixed effect model),

2. Hausman test (let you choose between Random effect and Fixed effect model),

3. Lagrange Multiplier Test (let you choose between OLS and Random effect model).

We developed the following hypotheses:

Hp1: IA, IU, CatH, HIS, and LEX affect the HEPI, according to literature review we expect to find a positive influence (reduction) of IA, IU, CatH, HIS, and LEX on HEPI. This is plausible because the more increase the life expectancy, the more people want to maintain their health finding information on the Internet. HIS is strictly connected to the availability of infrastructures (IA) and technology (CatH) and to the frequency of Internet usage (IU).

$\mathrm{Hp2}$ : there is a different pattern in individual behaviours across country.

\section{RESULTS}

According to the test conducted above, the null hypotheses was rejected in the F-test and in Hausman Test. This confirm that fixed effect model is preferable respect to OLS and Random Effect. In addition, we can state that, according to the F-test and Hausman Test, conducted on Individual fixed effect model and on Time fixed effect model, that the second model is preferable.

In the Time fixed effect model, HEPI raise constantly, while an increment of IA, HIS and LEX have the opposite effect. When individuals increase the possibility to access to the Internet and acquire more information about health, they are causing a reduction of health-care cost per capita, the same impact seems to have also life expectancy. In this case our first hypothesis is confirmed. 
Our second hypothesis cannot be confirmed, the test conducted suggests that there is no difference between country, this is also confirmed by the absence of significance in the Fixed effect (Individual) model.

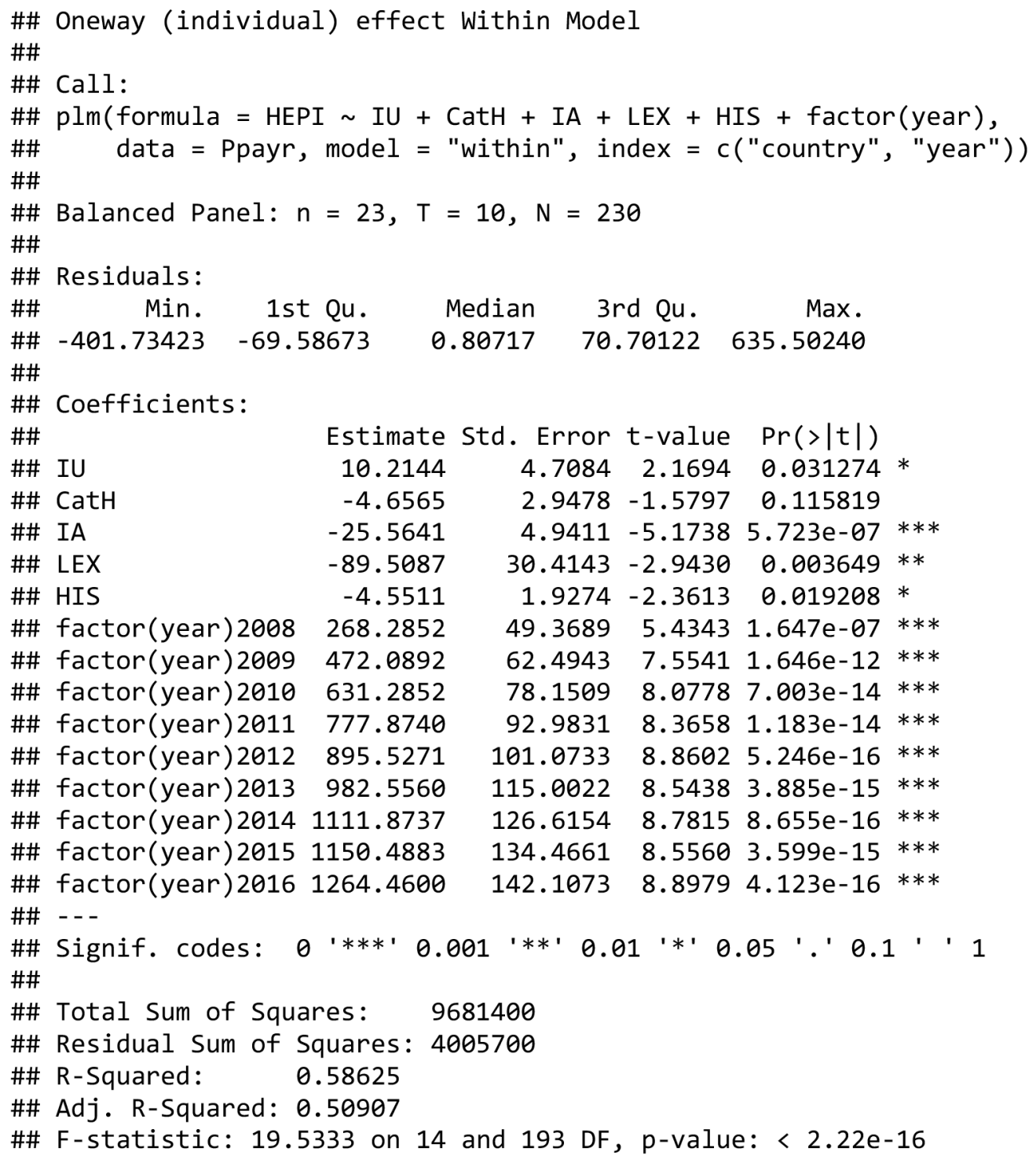

\section{CONCLUSION}

Health-care expenditures are constantly increasing, just as life expectancy in Europe, and individuals want to live longer and healthier. For these reasons they try to get much more information on different resources, the Internet is the most accessible and easy-to-use. In this paper we analysed the influence of some barriers of Digital Divide and Health Information Seeking Online on Health-care Expenditures. The results highlighted significative impact of Internet Access, Life Expectancy, Internet Usage and Health Information Seeking. This can be considered a starting point for further researches in this field. 


\section{REFERENCES}

[1] W. H. Organization, 'World health statistics 2018: monitoring health for the SDGs, sustainable development goals', Geneva, 2018.

[2] Y. N. Harari, 21 Lessons for the 21st Century. London: Vintage, 2019.

[3] OECD, How's Life in the Digital Age? OECD, 2019.

[4] G. Gravili, M. Benvenuto, A. Avram, and C. Viola, 'The influence of the Digital Divide on Big Data generation within supply chain management', Int. J. Logist. Manag., vol. 29, no. 2, pp. 592-628, 2018.

[5] Marco Benvenuto, Carmine Viola, and Francesco Sambati, 'A New Social and Technological Paradigm to Assess Chronic Patient Management Process: Preliminary Results', Manag. Stud., vol. 5, no. 6, 2017.

[6] M. R. Giovagnoli et al., 'Diagnostic and therapeutic path of breast cancer: Effectiveness, appropriateness, and costs - Results from the DOCMa study', Clin. Interv. Aging, vol. 10, 2015.

[7] L. Gastaldi and M. Corso, 'International Journal of Engineering Business Management Smart Healthcare Digitalization: Using ICT to Effectively Balance Exploration and Exploitation Within Hospitals Regular Paper', pp. 1-13, 2012.

[8] V. N. Slev, P. Mistiaen, H. R. W. Pasman, I. M. V. Leeuw, C. F. van Uden-Kraan, and A. L. Francke, 'Effects of eHealth for patients and informal caregivers confronted with cancer: A meta-review', Int. J. Med. Inform., vol. 87, pp. 54-67, Mar. 2016.

[9] P. Norris, Digital Divide. Cambridge: Cambridge University Press, 2001.

[10] W. Ryder, M. and Brent, 'Affordances and Constraints of the Internet for Learning and Instruction', Present. to Assoc. Educ. Commun. Technol. Indianapolis, IN., 1996.

[11] S., DiMaggio, P., Hargittai, E., Celeste, C., and Shafer, 'Digital Inequality: From Unequal Access to Differentiated Use.', in Social Inequality, K. N. Ed., Ed. New York: Russell Sage Foundation., 2004, p. '355-400.

[12] P. DiMaggio, E. Hargittai, W. R. Neuman, and J. P. Robinson, 'Social Implications of the Internet', Annu. Rev. Sociol., vol. 27, no. 1, pp. 307-336, Aug. 2001.

[13] R. Whitaker, The End of Privacy: How Total Surveillance is Becoming a Reality. New York: The New Press, 2000.

[14] E. J. Wilson, 'Closing the digital divide: an initial review. Briefing the President', Washington DC Internet Policy Inst., 2000.

[15] J. Cooper, 'The digital divide: the special case of gender', J. Comput. Assist. Learn., vol. 22, no. 5, pp. 320-334, Sep. 2006.

[16] H. Ono and M. Zavodny, 'Gender and the Internet *', Soc. Sci. Q., vol. 84, no. 1, pp. 111121, Mar. 2003.

[17] S. Dutta and B. Bilbao-Osorio, The Global Information Technology Report 2012 Living in a Hyperconnected World. 2012.

[18] R. Broadbent and T. Papadopoulos, 'Impact and benefits of digital inclusion for social housing residents', Community Dev., vol. 44, no. 1, pp. 55-67, 2013.

[19] Y. Neumark, C. Lopez-Quintero, B. S. Feldman, A. J. Hirsch Allen, and R. Shtarkshall, 'Online health information seeking among Jewish and Arab adolescents in Israel: Results from a national school survey', J. Health Commun., vol. 18, no. 9, pp. 1097-1115, 2013.

[20] J. Choudrie, G. Ghinea, and V. N. Songonuga, 'Silver surfers, e-government and the digital divide: An exploratory study of UK local authority websites and older citizens', Interact. Comput., vol. 25, no. 6, pp. 417-442, 2013. 
[21] S. Jiang and R. L. Street, 'Factors Influencing Communication with Doctors via the Internet: A Cross-Sectional Analysis of 2014 HINTS Survey', Health Commun., vol. 32, no. 2, pp. 180-188, 2017.

[22] Y. Zhang, Z. Lin, X. Li, T. Xiaoming, Y. Zhou, and X. Zhang, 'Factors Affecting ICT Use in Health Communication among the Older Population in Jiangsu, China', Libri, vol. 69, no. 1, pp. 41-53, 2019.

[23] D. Haluza, M. Naszay, A. Stockinger, and D. Jungwirth, 'Digital Natives Versus Digital Immigrants: Influence of Online Health Information Seeking on the Doctor-Patient Relationship', Health Commun., vol. 32, no. 11, pp. 1342-1349, 2017.

[24] Y. Feng and W. Xie, 'Digital divide 2.0: The role of social networking sites in seeking health information online from a longitudinal perspective', J. Health Commun., vol. 20, no. 1, pp. 60-68, 2015.

[25] A. Sato and J. Costa-i-Font, 'Social networking for medical information: A digital divide or a trust inquiry?', Heal. Policy Technol., vol. 2, no. 3, pp. 139-150, 2013.

[26] K. M. Hallows, 'Health information literacy and the elderly: Has the Internet had an impact?', Ser. Libr., vol. 65, no. 1, pp. 39-55, 2013.

[27] C. Shah and G. Marchionini, 'Awareness in CIS', Int. Rev. Res. Open Distance Learn., vol. 14, no. 4, pp. 90-103, 2013.

[28] M. Manierre, 'Examining the Relationship Between Flexible Resources and Health Information Channel Selection', Health Commun., vol. 31, no. 1, pp. 22-34, 2016.

[29] Y. Croissant and G. Millo, Panel Data Econometrics with R. John Wiley \& Sons Ltd, 2018. 